\title{
Editorial: Thematic series on best articles from IFIPTM and PST
}

\author{
Carmen Fernandez-Gago ${ }^{1}$ and Christian Damsgaard Jensen ${ }^{2^{*}}$
}

\author{
* Correspondence: \\ Christian.Jensen@imm.dtu.dk \\ ${ }^{2}$ Technical University of Denmark, \\ Kongens Lyngby, Denmark \\ Full list of author information is \\ available at the end of the article
}

The field of computational trust and trust management is being addressed in a wide range of academic disciplines ranging from Computer-Supported Cooperative Work (CSCW) and service selection on the World Wide Web through reputation and recommendation systems to computer and network security. Trust and trust management are therefore among the topics of interest for many large international and specialized conferences like the International Conference on Trust and Trustworthy Computing (Trust), the International Conference on Trust, Privacy \& Security in Digital Business (TrustBus), the Annual Conference on Privacy, Security and Trust (PST), and the IFIP WG 11.11 International Conference on Trust Management (IFIPTM) have established themselves over the past decade. In particular, the two conferences mentioned last (PST and IFIPTM), have a comprehensive scope that results in a wide range of trust related topics covered at the conferences.

This volume includes invited extensions of some of the best papers presented at the $7^{\text {th }}$ International Conference on Trust Management (IFIPTM'14) and the $11^{\text {th }}$ Annual Conference on Privacy, Security and Trust (PST 2014). Having achieved among the highest scores when reviewed for the conferences, these extended papers were submitted to a second round of reviews before being accepted for this special issue.

The contributions from IFIPTM cover computational trust, social aspects of trust management as well as trending topics such as the use of trust for cloud computing. The contributions from PST address a diverse set of problems, such as determining the trustworthiness of crowdsourced information resources, measuring and communicating the trustworthiness of online information, establishing trust in interactive ubiquitous display environments and detecting possible Sybil attacks in vehicular networks through platoon dispersal. The broad set of topics covered by these papers illustrates both the importance of trust and trust management in diverse application areas, and the multidisciplinarity of the approaches that are necessary to address these trust issues. 
We found these papers very interesting and the discussions that they engendered at the conferences particularly enlightening, so we hope that you will also enjoy them.

Carmen Fernandez-Gago (Program Co-Chair, IFIPTM'13)

Christian Damsgaard Jensen (Program Co-Chair, Trust theme at PST 2013)

Author details

${ }^{1}$ University of Malaga, Malaga, Spain. ${ }^{2}$ Technical University of Denmark, Kongens Lyngby, Denmark.

Received: 10 April 2014 Accepted: 10 April 2014

Published: 20 May 2014

doi:10.1186/2196-064X-1-2

Cite this article as: Fernandez-Gago and Jensen: Editorial: Thematic series on best articles from IFIPTM and PST.

Journal of Trust Management 2014 1:2.

\section{Submit your manuscript to a SpringerOpen ${ }^{\circ}$} journal and benefit from:

- Convenient online submission

- Rigorous peer review

- Immediate publication on acceptance

- Open access: articles freely available online

- High visibility within the field

- Retaining the copyright to your article

Submit your next manuscript at $>$ springeropen.com 